NBER WORKING PAPER SERIES

CRIME AND PUNISHMENT AGAIN:

THE ECONOMIC APPROACH

WITH A PSYCHOLOGICAL TWIST

William T. Dickens

Working Paper No. 1884

NATIONAL BUREAU OF ECONOMIC RESEARCH

1050 Massachusetts Avenue

Cambridge, MA 02138

Apr $i 11986$

I would like to thank Philip Bokovoy and Alan McArthur for research assistance and helpful comments and Kevin Lang and an anonymous referee for several suggested improvements. I would also like to thank the Institute of Industrial Relations at Berkeley for generous research support. The research reported here is part of the NBER's research program in Labor studies. Any opinions expressed are those of the author and not those of the National Bureau of Economic Research. 


\title{
Crime and Punishment Again: \\ The Economic Approach with a Psychological Twist
}

\begin{abstract}
Akerlof and Dickens (1982) suggested that in a model of criminal behavior which considered the effects of cognitive dissonance, increasing the severity of punishment could increase the crime rate. This paper demonstrates that that conjecture was correct. With cognitive dissonance, people may have to rationalize not committing crimes under normal circumstances if punishment is not severe. The rationalization may lead them to underestimate the expected utility of committing crimes when opportunities present themselves. If punishment is severe, then rationalization may not be necessary and people may be more likely to commit crimes when opportunities arise.
\end{abstract}

William T. Dickens $\mathrm{NBER}$ 1050 Massachusetts Avenue Cambridge, MA 02138 


\section{Introduction}

For homo economus decisions are always easy. The tasks economic theorists confront him with are well defined optimization problems where a straightforward application of decision calculus gives a definite answer. For homo sapiens decision making is nowhere near as simple. Most decisions involve significant qualitative evidence which defies systematization. In the end we are almost always uncertain. After a decision is made we often worry whether our judgment was good. Psychological studies of cognitive dissonance suggest that this worry is unpleasant and that we resolve this worry by systematically altering our beliefs to convince ourselves that the original decision was correct without doubt. Elliot Arronson (1979, chapter 4) describes a number of these experiments.

For those interested in the economic theory of crime one set of experiments is particularly interesting. In those experiments children were told not to play with a very desirable toy. One group was threatened with severe punishment and another with mild punishment for disobedience. The children were then allowed to play in a room containing the toy for some time. Several weeks later the children were again put in the room with the toy, only this time the threat of punishment was withdrawn. Those who had been threatened with the more severe punishment proved more likely to play with the forbidden toy than those threatened with mild punishment [for example, see Jonathan Freedman (1965)]. The cognitive dissonance interpretation is that those threatened with only mild punishment needed to convince themselves that the toy was really not very desirable to make themselves comfortable with their decision not to play with the toy. Those who were threatened with severe punishment had no such need. 
Akerlof and Dickens (1982) conjecture that in an economic model of crime which incorporates cognitive dissonance, increasing punishment could decrease compliance with the law. This paper presents a model which demonstrates that that conjecture was correct. The behavior is possible because increasing punishment decreases the need to reduce cognitive dissonance. When punishment is severe, psychic uncertainty is reduced and people no longer need to develop internal justifications for law-abiding behavior. Although increasing punishment will always lead to reduced crime rates above some level - it is possible that a minimum crime rate may be achieved with relatively little punishment in the range in which people are experiencing cognitive dissonance reactions.

II. The Mode1 in Words

At most times in people's lives crime probably doesn't pay. The chance of apprehension is too high, the expected gain is too low, and/or the knowledge of how to commit a crime is not there. But sometimes penple may be confronted with opportunities. A teenager may find out that a friend makes big money working for a car theft ring. The same week that teenager may come across an expensive car with the keys in the ignition. Alternatively, a shopper may find his or herself with a very valuable item, close to the door, with no salesperson in sight.

If during normal times the advantages of not committing a crime are not completely clear, people may be uncomfortable with their decisions to be honest. For someone who is not a career criminal, the decision to commit a crime involves a great deal of uncertainty. How will I feel after I've committed the crime? Will I feel very guilty? What will my friends think of me? What are the chances that I will be caught? What would the 
rest of my life be like if I were caught? The psychic cost of this uncertainty may lead people to change their beliefs to convince themselves that they have made the right decision without a doubt.

Having modified their beliefs to make themselves comfortable with their decision not to commit crimes under normal circumstances, people may be less likely to commit crimes when real opportunities come along. But, if the level of punishment for committing a crime is so severe that there is no doubt in people's minds as to why they are not committing crimes under normal circumstances, they need not develop any internal justification for not committing crimes and may be more likely to engage in criminal behavior if the opportunity arises.

Unfortunately this logic is not conclusive. We cannot be certain that people will not in some sense recognize this possibility and persist in their discomforting beliefs in order to capture the valuable opportunity to commit the crime if it arises. In fact, the analysis below shows that people may do this but there will still be a range of punishments where increasing punishment increases the crime rate.

\section{A Formal Mode1}

People live two periods. In both periods they have the opportunity to commit a crime. People choose whether or not to commit a crime to maximize expected utility. Each individual's best estimate of the utility value of the crime is $\mathrm{v}$. In the first period (corresponding to "normal circumstances" in the discussion above), the probability of being apprehended if one commits a crime is $\mathrm{p}_{1}$ and the utility cost if one is apprehended is $c$. In the second period one gets an "opportunity" to commit a crime. The opportunity consists of a lower probability of 
apprehension, $\mathrm{p}_{2}$. For the purpose of exposition it will be assumed that $\mathrm{p}_{2}$ is a random variable described by a continuous distribution function whose domain is the interval $\left[\mathrm{p}_{1}, 0\right]$. It will be assumed that at the beginning of period 1 people know the form of the distribution but not their draw from it. That they will discover at the beginning of period 2 . This defines a simple model of a decision about criminal behavior. Without any further complication it would yield the standard results that if $\mathrm{p}_{1} \mathrm{c} \geqq \mathrm{v}$ then no crimes will be committed in the first period. ${ }^{1}$ The crime rate in the second period would be equal to the probability that $\mathrm{p}_{2}$ $<\mathrm{v} / \mathrm{c}$. Increasing $\mathrm{c}$, the cost imposed by punishment, or changing the distribution of $\mathrm{p}_{2}$ so that values less than $\mathrm{v} / \mathrm{c}$ are less likely would decrease the crime rate. Introducing consideration of cognitive dissonance changes this.

To bring cognitive dissonance into the model a few additional assumptions are necessary. In its absence the decision to commit the crime in the first period is independent of the decision to commit it in the second. But, when cognitive dissonance is introduced, people's decisions in the first period may influence their choice of beliefs. Since beliefs formed in the first period will be assumed to affect behavior in the second period, the two decisions will no longer be independent. Following Akerlof and Dickens (1982) it will be assumed that people have perfect foresight about the nature of their cognitive dissonance reaction and the effects of changing their beliefs on their future behavior. It will be assumed that people take all this into account in deciding whether or not to commit the crime in the first period. It will be also be assumed that people may choose not to have a cognitive dissonance reaction if it doesn't increase their expected utility. This omniscience may seem incongruent with the 
notion of cognitive dissonance. Certainly cognitive dissonance is an unconscious reaction rather than a conscious decision. There are two justifications for this approach. The first is that even though the reaction is unconscious, that does not mean that the consequences of a decision aren't in some sense foreseen and taken into account in making the "decision." Unconscious decisions are not necessarily irrational or short-sighted. Psychological theory views unconscious decisions as being, for the most part, functional (Simon, 1978, p. 3).$^{2}$ The second justification is simply that the exposition is easier if we begin with this assumption and then relax it in parts. This exercise is carried out in section VI.

Since the decision to commit a crime in the second period may depend on the decision in the first period and since we are assuming people foresee these effects, the decision to commit the crime in the first period is based on the sum of the expected utilities for the two periods. The effects of cognitive dissonance on expected utility are implemented with three additional assumptions. First, people can change their beliefs about the value of the crime (v) between the two periods. They may want to do this because of the second assumption -- that if they aren't sufficiently sure of their decisions they will suffer a dissonance cost (s). To implement the notion of "sufficiently sure" it will be assumed that if a person does not commit the crime and the subjective expected utility in the first period is not at least d utils greater than the subjective expected utility if the crime was committed, then the dissonance cost will be experienced. If the crime is committed, then the dissoance cost will be experienced if the subjective expected utility isn't d units greater than if it is not. Since whether the dissonance cost is experienced depends on 
differences in subjective, as opposed to true expected, utilities, people can always avoid the dissonance cost by believing the value of the crime is either high or low.

Adding a psychic cost for uncertainty and allowing people to alter their beliefs about the value of a crime may or may not affect the behavior of the model. If people can change their beliefs about the value of a crime in period 1 without affecting their beliefs about the value in period 2 , it would always be possible to make the utility maximizing choice of committing the crime or not committing it in the first period and still avoid the dissonance cost s. They could convince themselves that the value of the crime was either very high or very low depending on whether they committed the crime or didn't. In the second period they would be free to make the utility maximizing choice again with correct beliefs about $\mathrm{v}$ - The effects of enforcement on crime rates would be unchanged from the model which did not take account of the psychological considerations. If, on the other hand, what people believe about $v$ in the first period affects what they believe about it in the second period, there may be a cost to modifying one's beliefs -- "wrong" decisions in the second period. For the rest of this paper we will adopt as the third assumption that whatever one decides to believe about $v$ in the first period must also be what one believes in the second period and that people's actions in the second period must be consistent with their beliefs. The justification for this assumption comes from the motivation for the two-period model. Period 1 represents normal circumstances and period 2 represents a transient departure from them. If beliefs are going to rationalize behavior in the full range of normal circumstances they will necessarily be 
very general and are likely to extend to the situations of transient opportunity.

Putting the above discussion together, and assuming that the probability of apprehension and the distribution of $\mathrm{P}_{2}$ are independent, we have the following statement of the individual's decision problem:

Choose whether or not to commit a crime ( $c c$ for commit crime, nc for no crime) and beliefs about $v,\left(v^{b}\right)$ to maximize.

$$
\begin{aligned}
& E(u)=\left\{\begin{array}{ll}
v_{v}-p_{1} c & \text { if } c c \\
0 & \text { otherwise }
\end{array}\right\}+\left[v-c E\left(p_{2} \mid p_{2}<\frac{v^{b}}{c}\right)\right] \operatorname{Prob}\left(p_{2}<\frac{v^{b}}{c}\right)- \\
& \left\{\begin{array}{l}
\mathrm{s} \text { if } \mathrm{cc} \text { and } \mathrm{v}^{\mathrm{b}}-\mathrm{p}_{1} \mathrm{c}<\mathrm{d} \text { or } \\
\text { if } \mathrm{nc} \text { and } \mathrm{p}_{1} \mathrm{c}-\mathrm{v}^{\mathrm{b}}<\mathrm{d} \\
0 \text { otherwise }
\end{array}\right.
\end{aligned}
$$

The first term is the expected value of committing a crime in the first period. The bracketted part of the second term is the expected value of committing a crime in the second period and $\operatorname{Prob}\left(\mathrm{p}<\mathrm{v}^{\mathrm{b}} / \mathrm{c}\right)$ is the probability that the person will perceive the opportunity as worth taking. The last term reflects the psychic costs of dissonance.

If we have a group of people with the same original beliefs about $v$, the crime rate in the first period will be $100 \%$ if they commit the crime or 0 if they do not. In the second period the crime rate will be equal to $\operatorname{Prob}\left(\mathrm{p}_{2}<\mathrm{v}^{\mathrm{b}} / \mathrm{c}\right)$. 
IV. Analysis of the Model

If $\mathrm{v}>\mathrm{p}_{1} \mathrm{c}$, people will maximize expected utility by committing the crime in both periods. Since they always want to commit the crime in the second period they can believe the crime is as worthwhile as necessary to avoid the dissonance cost.

If the value of the crime is very low, so that $v \leqq p_{1} c-d$, it is clearly rot worth committing in the first period. Further, since the value of the crime is so small, there is no dissonance cost to believing the truth and making optimal. decisions in the second period.

It is on $1 \mathrm{y}$ if $\mathrm{p}_{1} \mathrm{c} \geqq \mathrm{v}>\mathrm{p}_{1} \mathrm{c}-\mathrm{d}$ that the cognitive dissonance reaction may matter. The possibility that increasing the severity of the punishment in this range may increase the crime rate can be demonstrated in two steps. First, possible behavior can be broken down into four classes. Peopie may either believe the truth and suffer cognitive dissonance, or convince themselves of something other than the truth. In either case they may commit the crime in the first period or not. If they choose not to commit the crime and avoid the dissonance cost by believing the value of the crime is less than it is (setting $v^{b}<v$ ), it can be shown that the crime rate will increase if $c$ is increased. Second, it can be shown that there will always exist some values of $c$ for which people will maximize expected utility by not committing the crime and setting $v^{b}=p_{1} c-d<v$. Thus, it will always be the case that for some values of $c$ the crime rate will increase with the severity of punishment.

To see that people who choose not to commit a crime and to believe $\mathrm{v}^{\mathrm{b}}<\mathrm{v}$ to avoid the dissonance cost will choose $\mathrm{v}^{\mathrm{b}}$ to equal $\mathrm{p}_{1} \mathrm{c}-\mathrm{d}$, note that 


$$
\begin{aligned}
& E\left(\mathrm{u} \mid \mathrm{nc}, \mathrm{v}^{\mathrm{b}} \neq \mathrm{v}\right)=\left[\mathrm{v}-\mathrm{cE}\left(\mathrm{p}_{2} \mid \mathrm{p}_{2}<\frac{\mathrm{v}^{\mathrm{b}}}{\mathrm{c}}\right)\right] \operatorname{Pr}\left(\mathrm{p}_{2}<\frac{\mathrm{v}^{\mathrm{b}}}{\mathrm{c}}\right) \\
& =v \int_{0}^{\frac{v^{b}}{c}} \phi\left(p_{2}\right) d p_{2}-c \int_{0}^{\frac{v^{b}}{c}} p_{2} \phi\left(p_{2}\right) d p_{2}
\end{aligned}
$$

(where $\phi$ is the density function for $p_{2}$ ). The derivative of expected utility with respect to $\mathrm{v}^{\mathrm{b}}$ is

$$
\frac{\partial E(u \mid n c)}{\partial v^{b}}=\frac{v \phi\left(\frac{v^{b}}{c}\right)}{c}-\frac{v^{b} \phi\left(\frac{v^{b}}{c}\right)}{c}
$$

which is positive as long as $v^{b}<v--$ the closer to the truth are one's beliefs, the fewer mistakes one will make and the better off one will be. So to maximize expected utility while avoiding the dissonance cost, people will choose $v^{b}$ as large as possible subject to the constraint that $\mathrm{cp}_{1}$ $\mathrm{v}^{\mathrm{b}} \geqq \mathrm{d}$ or $\mathrm{v}^{\mathrm{b}}=c \mathrm{p}_{1}-\mathrm{d}$. In this case the crime rate in the second period is equal to

$$
\operatorname{Pr}\left(\mathrm{p}_{2}<\mathrm{v}^{\mathrm{b}} / \mathrm{c}\right)=\operatorname{Pr}\left(\mathrm{p}_{2}<\mathrm{p}_{1}-\mathrm{d} / \mathrm{c}\right),
$$

which is increasing in $c$, so increasing the severity of punishment raises the crime rate in the second period. It remains to be shown that people will choose to behave this way in some situations.

Consider a severity level of punishment of

$$
c=v+d / p_{1}-\varepsilon
$$

where $\varepsilon$ is a small number. At this point the expected utility of someone who does not commit the crime in the first period and believes $v^{b}=$ $c \mathrm{p}_{1}-\mathrm{d}$ to avoid the dissonance cost is

$$
\mathrm{E}\left(\mathrm{u} \mid \mathrm{nc}, \mathrm{v}^{\mathrm{b}} \neq \mathrm{v}\right)=\left[\mathrm{v}-\mathrm{cE}\left(\mathrm{p}_{2} \mid \mathrm{p}_{2}<\mathrm{v}^{\mathrm{b}} / \mathrm{c}\right)\right] \operatorname{Pr}\left(\mathrm{p}_{2}<\mathrm{v}^{\mathrm{b}} / \mathrm{c}\right)
$$


For someone who does not commit the crime and believes the truth, expected utility is

$$
E\left(\mathrm{u} \mid \mathrm{nc}, \mathrm{v}^{\mathrm{b}}=\mathrm{v}\right)=\left[\mathrm{v}-\mathrm{cE}\left(\mathrm{p}_{2} \mid \mathrm{p}_{2}<\mathrm{v} / \mathrm{c}\right)\right] \operatorname{Pr}\left(\mathrm{p}_{2}<\mathrm{v} / \mathrm{c}\right)-\mathrm{d}
$$

Since

$$
\mathrm{v}^{\mathrm{b}}=\mathrm{cp_{1 }}-\mathrm{d}=\mathrm{v}-\mathrm{p}_{1} \varepsilon
$$

by choosing $\varepsilon$ sufficiently small, the difference $E\left(u \mid n c, v^{b} \neq v\right)-$ $E\left(u \mid n c, v^{b}=v\right)$ can be made arbitrarily close to $d$. Thus for some range of values of $c<v+d / p_{1}$,

$$
\mathrm{E}\left(\mathrm{u} \mid \mathrm{nc}, \mathrm{v}^{\mathrm{b}} \neq \mathrm{v}\right)>\mathrm{E}\left(\mathrm{u} \mid \mathrm{nc}, \mathrm{v}^{\mathrm{b}}=\mathrm{v}\right)
$$

Next consider the case where someone commits the crime in the first period and believes the truth. His or her expected utility is

$$
\begin{gathered}
E\left(\mathrm{u} \mid \mathrm{c}, \mathrm{v}^{\mathrm{b}}=\mathrm{v}\right)=\left[\mathrm{v}-\mathrm{cE}\left(\mathrm{p}_{2} \mid \mathrm{p}_{2}<\mathrm{v} / \mathrm{c}\right)\right] \operatorname{Pr}\left(\mathrm{p}_{2}<\mathrm{v} / \mathrm{c}\right)+\mathrm{v}-\mathrm{p}_{1} \mathrm{c}-\mathrm{d} \\
=\mathrm{E}(\mathrm{u} \mid \mathrm{nc}, \mathrm{v}=\mathrm{v})+\mathrm{v}-\mathrm{p}_{1} \mathrm{c} .
\end{gathered}
$$

Since $v-p_{1} c<0, E\left(u \mid n c, v^{b} \neq v\right)>E\left(u \mid n c, v^{b}=v\right)$ implies $E\left(u \mid n c, v^{b} \neq v\right)>E\left(u \mid c, v^{b}=v\right)$.

Finally, note that

$$
\mathrm{E}\left(\mathrm{u} \mid \mathrm{c}, \mathrm{v}^{\mathrm{b}} \neq \mathrm{v}\right)=\left[\mathrm{v}-\mathrm{cE}\left(\mathrm{p}_{2} \mid \mathrm{p}_{2}<\mathrm{v} / \mathrm{c}\right)\right] \operatorname{Pr}\left(\mathrm{p}_{2}<\mathrm{v}^{\mathrm{b}} / \mathrm{c}\right)+\mathrm{v}-\mathrm{p}_{1} \mathrm{c}
$$

Once again, $v-p_{1} c<0$ in this range. From equation (1) $v=v^{b}$ maximizes the first term so $\left[\mathrm{v}-\operatorname{cE}\left(\mathrm{p}_{2} \mid \mathrm{p}_{2}<\mathrm{v} / \mathrm{c}\right) \operatorname{Pr}\left(\mathrm{p}_{2}<\mathrm{v} / \mathrm{c}\right)\right]$ $>\mathrm{E}(\mathrm{u} \mid \mathrm{c}, \mathrm{v} \neq \mathrm{v})$ when $\mathrm{c}=\mathrm{v}+\mathrm{d} / \mathrm{p}_{1}$. Since by choosing $\varepsilon$ sufficiently close to zero, $\mathrm{E}\left(\mathrm{u} \mid \mathrm{nc}, \mathrm{v}^{\mathrm{b}} \neq \mathrm{v}\right)$ can be made arbitrarily close to $\left[v-c E\left(p_{2} \mid p_{2}<v / c\right) \operatorname{Pr}\left(p_{2}<v / c\right)\right]$, it follows that 


$$
E\left(u \mid n c, v^{b} \neq v\right)>E\left(u \mid c, v^{b} \neq v\right)
$$

for some values of $c<v+d / p_{1}$. Thus for some range of values of $c$, people will maximize expected utility by not committing the crime and believing that the value of the crime is less than it is to avoid the dissonance cost. When people behave this way, increasing the severity of punishment increases the crime rate.

\section{An Example}

To illustrate these possibilities, consider the case where $\mathrm{p}_{2}$ is uniformly distributed on the interval $\left[\mathrm{p}_{1}, 0\right]$. In that case

$$
E\left(p_{2} \mid p_{2}<a\right)=\frac{1}{2} a
$$$$
\operatorname{Pr}\left(\mathrm{p}_{2}<\mathrm{a}\right)=\mathrm{a} / \mathrm{p}_{1} \quad \text { for } 0<\mathrm{a} \leqq 1
$$

$\mathrm{E}\left(\mathrm{p}_{2}\right)=\frac{1}{2} \mathrm{p}_{1}$

Using the quadratic formula and ruling out values which fall outside the range $\left(v / p_{1}, v+d / p_{1}\right)$

$$
c^{*}=\frac{s+v+d-\sqrt{(s+v+d)^{2}-(v+d)^{2}}}{p_{1}}
$$

and

$$
c^{\prime}=\frac{v-d+\sqrt{(v-d)^{2}+2\left(v d+d^{2}\right)}}{2 p_{1}},
$$

where $c^{*}$ is the value of $c$ for which $E\left(u \mid n c, v^{b} \neq v\right)=E\left(u \mid n c, v=v^{b}\right)$ and $c^{\prime}$ is the value for which $E\left(u \mid n c, v^{b} \neq v\right)=E\left(u \mid c, v^{b} \neq v\right)$. Since 
$\mathrm{E}\left(\mathrm{u} \mid \mathrm{nc}, \mathrm{v}^{\mathrm{b}}=\mathrm{v}\right)>\mathrm{E}\left(\mathrm{u} \mid \mathrm{c}, \mathrm{v}^{\mathrm{b}}=\mathrm{v}\right)$ for values of $\mathrm{c}>\mathrm{v} / \mathrm{p}_{1}$ and $\mathrm{E}(\mathrm{u} \mid \mathrm{c}, \mathrm{v} \neq \mathrm{v} \neq \mathrm{v}$ $\geqq E\left(u \mid c, v^{b}=v\right)$ for values of $c<v / p_{1}$, we need not consider such behavior. If $c^{\prime}<c^{*}$ the top end of the range in which people commit the crime in the first period is given by the value of $c$ where $E\left(u \mid c, v^{b} \neq v\right)$ $=E\left(u \mid n c, v^{b}=v\right)$ which is

$$
\frac{2 v+s+\sqrt{(2 v+s)^{2}-3 v^{2}}}{3 p_{1}}
$$

Figures $1 a$ and $b$ show expected utilities and crime rates for different values of $c$ for the case where the value of the crime (v) is fifty utils, the dissonance cost (s) is ten utils, the probability of apprehension in period $1\left(p_{1}\right)$ is .1 , and the range of uncertainty (d) is 100 . For $c<593$ the crime rate in both periods is $100 \%$. At $c=593$ the crime rate drops to $84 \%$. for $593<c<1043$ the crime rate declines from $84 \%$ to $48 \%$. At 1043 the crime rate drops again to $4 \%$ and then increases to $35 \%$ in the range $1043<c<1500$. In this range increasing $p_{1}$ would also increase the crime rate. Increasing the probability of apprehension in period 2 would have the standard effect of decreasing the crime rate. Above 1500 the crime rate declines, although $c$ must be greater than 12,500 before the crime rate will again drop below the previous minimum of $4 \%$. If the range of uncertainty was wider, for example, if $d$ was equal to 150 , there would be a range (from $c=1250$ to 2000$)^{3}$ in which people would maximize utility by not committing the crime in the first period and believing the crime would produce negative utility $\left(\mathrm{v}^{\mathrm{b}}<0\right)$. In that case people will never commit the crime in the second period and the crime rate would be at a global minimum when $c$ is in the range 1250 to 2000 . 
VI. Some Extensions

What if people are unaware, when they are making decisions, that they may later have a cognitive dissonance reaction? In that case people will view the decision in the first period as independent of the derision in the second period and will never commit a crime in the first period if $\mathrm{v}<\mathrm{P}_{1} \mathrm{c}$. What if people always have a cognitive dissonance reaction if they are faced with a dissonance cost - the decision is unconscious and short-sighted? In that case people do not have the option of believing the truth if $E\left(u^{*} \mid \mathrm{nc}\right)-E(\mathrm{u} * \mid c c)<d$ and will always have a dissonance reaction in the range $\mathrm{v} / \mathrm{p}_{1} \leqq \mathrm{c} \leqq \mathrm{v}+\mathrm{d} / \mathrm{p}_{1}$. As a result, the range in which the crime rate is increasing in the severity of punishment may be wider. Allowing for uncertainty about other parameters complicates the analysis but as long as people cannot eliminate the dissonance cost without affecting their behavior, the possibility of more severe punishment increasing crime rates would persist.

The model presented above is sufficiently elaborate to show what types of behavior are possible when we consider cognitive dissonance. However, if the model is to be used as the basis for empirical or prescriptive studies, more work would need to be done. Differences between individuals with respect to many of the parameters of the decision problem would need to be introduced. To explore the question of the optimal choice of penalty and probability of detection, the model would need to consider the welfare consequences of the cognitive dissonance reaction in a more realistic way. In the model above there is no psychic cost incurred if one adopts beliefs consistent with one's actions. In fact, maintaining incorrect beliefs may also be costly and the choice of what to believe may involve trading off 
such costs, as well as the costs of incorrect decisions, for less psychic uncertainty.

\section{Conclusion}

Given these qualifications, what relevance does this analysis have for policy? Its primary contribution is in providing another explanation for some otherwise puzzling empirical results. Most studies indicate that increasing the likelihood of punishment deters crime, but increased punishment is not always associated with lower crime rates. This is Beyleveld's (1980, p. 306) conclusion after a survey of social science research on deterrence. Several other explanations have been proposed, but they can only explain higher crime rates for specific crimes or higher rates of recidivism. ${ }^{4}$ If future studies suggest that increasing punishment does not reduce the number of first-time offenders, then cognitive dissonance may be playing a role in determining the level of criminal activity. If it is, then the most effective way to reduce criminal activity is to reduce the number and the attractiveness of opportunities to commit crimes. Trying to reduce the crime rate by increasing the severity of punishment could have disastrous consequences -- it could cause a leap in the crime rate as people are transformed from internally motivated law abiders into criminal opportunists. 


\section{Footnotes}

* I would 1ike to thank Phillip Bokovoy and Alan McArthur for research assistance and helpful comments and Kevin Lang and an anonymous referee for several suggested improvements. I would also like to thank the Institute of Industrial Relations at Berkeley and the National Science Foundation for generous research support.

1. It is assumed here and elsewhere in this paper that a person will not commit a crime if the expected utility is exactly equal to that if they do not commit the crime.

2. In economics we usually use the term rational to mean making the best possible use of available information. In this sense it is clear that many unconscious decision processes are as rational, if not more rational, than conscious processes. Milton Friedman's famous story of the billiards player who makes perfect three-cushion shots without formal analysis or the pilot who corrects the airplanes course without consciously considering the extremely complicated physics problem involved in the control of an aircraft are two examples. Just because we are not consciously aware of the way in which a judgment is made does not mean that the process didn't involve the best possible use of available information.

3. Note that the lower end of this range is not given by the solution to the quadratic since for values of $c<1500, E\left(u \operatorname{lnc}, v^{b} \neq v\right)=0$.

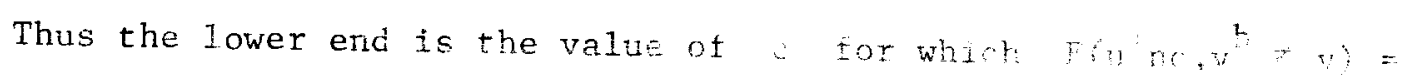
$E\left(u: n c, v^{L}=v\right)=0$. 


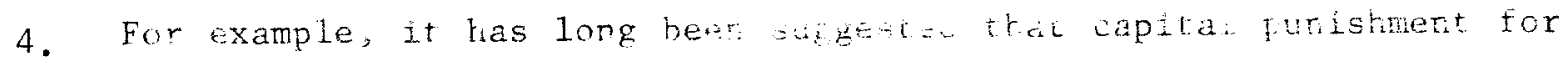
murder removes any incentive murderers may have for not repeating the crime. Jones and Stock. (1981) argue that if punishment involves reducing social status and integration, more severe reductions of social status and integration may increase recidivism. Finally, Myers (1980) argues that if prisons serve as training grounds for criminal skills or if legitimate job opportunities diminish, longer prison terms may lead to higher recidivism rates. 
Akerlof, George A. and Wiliiam T. Dickens, 1982, "The Economic Consequences of Cognitive Dissonance," American Economic Review, $3,307-319$.

Aronson, E1liot, 1980, The Social Animal, 3rd ed. (W.H. Freeman, San Francisco).

Beyleveld, Deryck, 1980, A Bibliography on General Deterrence (Saxon House, Teakfield, England).

Freedman, Jonathan, 1965, "Long-term Behavioral Effects of Cognitive Dissonance, "Journal of Experimental Social Psychology, 2, 14-55.

Jones, Stephen R.G. and James H. Stock, 1981, "Symbolic Interaction and Economic Exchange," mimeo, Berkeley, 1981.

Myers, Samuel L., 1980, "The Rehabilitation Effect of Punishment," Economic Inquiry, 3, 353-366.

Simon, Herbert A., 1978, "Rationality as Process and Product of Thought," American Economic Review, 2, 1-16. 
True Expected Utility

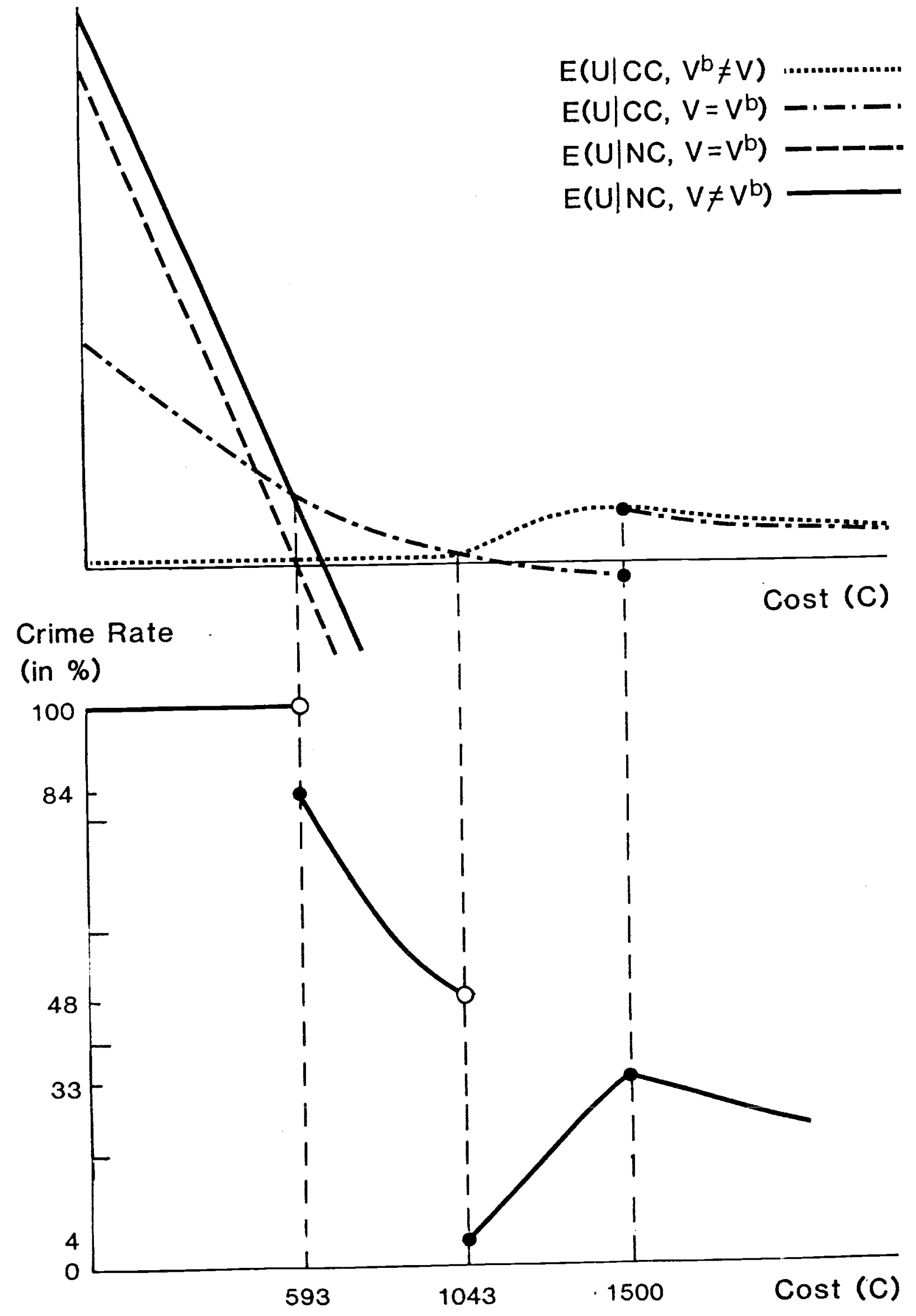

